\title{
HIV care and interdependence in Tanzania and Uganda
}

Book or Report Section

Accepted Version

Evans, R. and Atim, A. (2015) HIV care and interdependence in Tanzania and Uganda. In: Barnes, M., Brannelly, P., Ward, L. and Ward, N. (eds.) Ethics of care: critical advances in international perspective. The Policy Press, Chapter 12. ISBN 9781447316510 Available at http://centaur.reading.ac.uk/40521/

It is advisable to refer to the publisher's version if you intend to cite from the work. See Guidance on citing.

Publisher: The Policy Press

Publisher statement: This is a post-peer-review, pre-copy edited version of a chapter published in Ethics of care: critical advances in international perspective. Details of the definitive published version and how to purchase it are available online at: https://policy.bristoluniversitypress.co.uk/ethics-of-care.

All outputs in CentAUR are protected by Intellectual Property Rights law, including copyright law. Copyright and IPR is retained by the creators or other 
copyright holders. Terms and conditions for use of this material are defined in the End User Agreement.

\section{www.reading.ac.uk/centaur}

\section{CentAUR}

Central Archive at the University of Reading

Reading's research outputs online 
Book chapter in press in Ward, N., Ward, E. and Brannelly, P. (Eds), Renewing Care:

Critical International Perspectives on the Ethics of Care, The Policy Press.

\section{Chapter 12: HIV care and interdependence in Tanzania and Uganda}

\section{Authors: Ruth Evans and Agnes Atim}

Department of Geography and Environmental Science

University of Reading, UK.

\section{Contact details:}

Dr. Ruth Evans

Department of Geography and Environmental Science

University of Reading

Miller Building

Whiteknights PO Box 227

Reading RG6 6AB

Email: r.evans@ @reading.ac.uk

Tel: 01183787755

\section{Abstract (130 words)}

Within many communities in East Africa, people living with HIV are increasingly involved in delivering home-based care and healthcare for family members and peers. Such interdependent caring relations blur conventional boundaries between 'care-givers' and 'carerecipients', and constructions of 'service users' as dependent, passive recipients of healthcare. The participation of people living with HIV in healthcare provision, home-based care and peer support groups can enhance 'relational autonomy' for both care-givers and carerecipients, although such initiatives often play out in highly gendered ways. The care and support of people living with HIV, particularly the emotion work of caring, however, continues to be associated with women's and girls' assumed 'natural' nurturing roles and has been largely devalued and overlooked in HIV policy and practice to date.

\section{Key words:}

HIV care and support

People living with HIV (PLHA)

Service users

Participation in healthcare

East Africa 


\section{Introduction}

The principle of 'Greater Involvement of People Living with or Affected by HIV/AIDS' declared at the 1994 Paris AIDS Summit provided widespread international commitment (in rhetoric at least) to the participation of people living with HIV (PLHA) in tackling the epidemic at all levels. Organisations and networks of people living with HIV have grown rapidly in eastern and southern Africa in recent years in order to campaign for their rights to health. Research in Tanzania and Namibia has revealed that care is often a two-way process of both giving and receiving care, based on reciprocal, interdependent relations between PLHA and family members (Evans and Thomas, 2009). PLHA may provide home-based care for partners, children, other family members and peers with HIV, as well as receiving care themselves. Such interdependent caring relations blur conventional boundaries and assumptions about the needs and interests of 'care-givers' and 'care-recipients', while simultaneously revealing interconnected dependencies and power inequalities at a range of spatial scales.

This chapter draws on an ethics of care and emotional geographies to explore PLHA's caring relations and participation within families and communities in Tanzania and Uganda and partly draws on ideas discussed in Evans and Atim (2011). We discuss the findings of three qualitative studies. The first two studies (conducted by Ruth Evans), focused on children's caring roles in families affected by HIV; the first was based on interviews with 20 mothers/female relatives living with HIV, 22 young people who cared for them and 13 NGO workers in rural and urban areas of Tanzania. This was part of a larger study funded by the UK Economic and Social Research Council that investigated the experiences, needs and resilience of children caring for parents and relatives with HIV in Tanzania and the UK (see 
Evans and Becker 2009 for further information). The second study was focused on sibling caregiving in child- and youth-headed households in Tanzania and Uganda, based on interviews, focus groups and participatory workshops with a total of 73 participants, comprising 17 orphaned children and young people who were caring for their siblings, 17 younger siblings and 25 NGO workers and 14 community members. This study was funded by the University of Reading and by a Royal Geographical Society (with the Institute of British Geographers) (see Evans 2011; 2012 for further information).. The third study was based on doctoral research (conducted by Agnes Atim, part-funded by a University of Reading Social Sciences doctoral studentship) with a total of 80 participants, comprising interviews and focus groups with 18 men and 62 women living with HIV and 17 professionals in rural areas of Northern Uganda. .

In this chapter, we first give an overview of our theoretical approach. We then discuss how children and young people, who are often regarded as 'dependents', and women living with HIV, who are usually constructed as 'care-recipients' or 'service users', play crucial roles in providing mutual emotional support and physical care within the family and community in Tanzania and Uganda. We then explore the roles of PLHA in peer support, caregiving and healthcare delivery in East Africa. Several benefits of the participation of 'service users' are identified, alongside the challenges and constraints of achieving meaningful participation of PLHA in strategic decision-making processes.

\section{Theorising interdependent caring relations}

Disability theorists and feminists have highlighted the problematic nature of conventional notions of 'care', 'dependency' and 'autonomy' that establish a fixed binary opposition

(C) Ruth Evans and Agnes Atim, 5/3/15. Please cite as: Evans, R. and Atim, A. (in press) 'HIV care and interdependence in Tanzania and Uganda', in Ward, N., Ward, E. and Brannelly, P. (Eds), Renewing Care: Critical International Perspectives on the Ethics of Care, The Policy Press. 
between the roles of 'care-giver' and 'care-receiver' (Morris, 1991; Shakespeare, 1993). Researchers have recognised that caring relationships are rarely simply a 'one-way' process of 'giving' by one person to another, but rather are characterised by reciprocity and interdependence between the person living with illness or disability and the 'carer' (Evans and Becker, 2009). Tronto's (1993) and Sevenhuijsen's (1998) ethics of care recognise the interdependence and interconnectedness of human relations, responsibilities and practices of care. Caring is valued as a daily practice in everyone's lives and it is acknowledged that there is no absolute or fixed division of roles between 'care-giver' and 'care-receiver.

Recent work on emotional geographies recognises the ways that people living with illness or disability and their carers negotiate complex emotions (Davidson and Milligan, 2004; Evans and Thomas, 2009). Bondi suggests that the notion of 'empathic understanding' enables caregivers to 'imaginatively identify with care-recipients without confusing their own feelings with those they imagine to be felt by care-recipients. It is equally what enables carerecipients to imagine what it might be like for care-givers to do what they do' $(2008,260)$. She explains that this fosters good communication between caregivers and care-receivers which helps to ensure that care needs have been met, corresponding to Tronto's ethical value of 'responsiveness'.

Fine and Glendinning's (2005) understanding of 'relational autonomy' (Mackenzie and Stoljar, 2000) and Kittay's (2002) theorisation of the power relations imbued in notions of 'care' and 'dependency' are also helpful in exploring the participation of PLHA in care, support and advocacy at local, national and global levels. Fine and Glendinning (2005) suggest that 'independence' can be conceptualised as 'relational autonomy'; power should 4 (C) Ruth Evans and Agnes Atim, 5/3/15. Please cite as: Evans, R. and Atim, A. (in press) 'HIV care and interdependence in Tanzania and Uganda', in Ward, N., Ward, E. and Brannelly, P. (Eds), Renewing Care: Critical International Perspectives on the Ethics of Care, The Policy Press. 
not only be regarded as negative, but rather can be understood as 'capability', 'as a form of empowerment - "power to" not "power over"”(p.616). Empowerment is understood in terms of a person's agency and their capacity to do or affect something and 'make a difference'. Kittay (2002) distinguishes between 'inequality of power' and the 'exercise of domination' in caregiving; inequalities of power do not mean that abuse is inherent in the caring relationship, which is ideally based on mutual trust and responsibility. Domination, however, represents a breakdown of this mutual trust by either the worker [the paid or unpaid caregiver] or the charge [the care-recipient] (Fine and Glendinning, 2005, p.613).

Kittay (2002) suggests that a second level of dependency is based on the reliance of the charge and the dependency worker on 'the provider', who controls the resources needed to provide care and creates the conditions which devalue 'dependency work'. The state may be regarded as 'the provider', but in Tanzania, Uganda and other low-income countries in the global South, state welfare support is virtually non-existent and health systems are severely constrained, especially in post-conflict settings. In this context, the notion of a 'provider' could also encompass donor aid and global institutions and funding streams such as the US President's Emergency Fund for AIDS Relief and the Global Fund to fight AIDS, tuberculosis and malaria. The second level of dependency is thus characterised by power inequalities at the global and national scales that prevent equal access to healthcare and constrain the ability of governments and healthcare providers to provide support for all those who require assistance, as well as by social arrangements at the local level (Evans and Atim, 2011). This highlights the need to contextualise caring relations and institutions at multiple, interconnected scales, as we seek to do in this chapter. interdependence in Tanzania and Uganda', in Ward, N., Ward, E. and Brannelly, P. (Eds), Renewing Care: Critical International Perspectives on the Ethics of Care, The Policy Press. 


\section{Interdependent caring relations within families}

Recent research in Africa has revealed that care is often characterised by strong emotional connections between PLHA and those who care for them (Chimwaza and Watkins, 2004; Evans and Thomas, 2009). Many young people heading households shared the domestic and care work with their siblings, developing reciprocal relations of care and support within the home that could accommodate their schooling and livelihood activities. Rickson (aged 19) who was caring for two younger siblings commented:

"Since I stay with my two siblings, we have shifts. If I have time today I cook, so that s/he can be able to study. If it is tomorrow, I can study when s/he is cooking. The other day I study and s/he cooks. Just like that. So, we change shifts".

Many mothers with HIV and children caring for them in Tanzania reported that they had close, loving relationships and understood each other well. Children played a key role in providing emotional support to their mothers, siblings and other relatives living with HIV. Despite mothers' illness and the emotional support children provided, however, most children said that they turned to their mother for advice, guidance and support. Mothers/adult relatives with HIV retained their usual position of authority and responsibility for decision-making within the household, despite sometimes being nursed in bed for several months. The continued parenting role of mothers refutes negative assumptions about the competence of parents living with HIV to provide good care for their children (Evans and Atim, 2011).

Some mothers' and young people's narratives demonstrate a strong sense of empathy and understanding of the emotional pressures the other person in the caring relationship may be

(C) Ruth Evans and Agnes Atim, 5/3/15. Please cite as: Evans, R. and Atim, A. (in press) 'HIV care and interdependence in Tanzania and Uganda', in Ward, N., Ward, E. and Brannelly, P. (Eds), Renewing Care: Critical International Perspectives on the Ethics of Care, The Policy Press. 
experiencing. Husna, a mother with HIV, reflected on why Juliette (aged 20) had greater caring responsibilities than her other daughters: "I feel she is the one who understands my situation better. She is very compassionate. It is obvious that she really depends on me and I on her". Juliette, who was studying at a teacher training college away from home during term-time, commented on the emotional dimensions of her caring responsibilities:

Whenever I get a letter from home saying she is very poorly, I can't concentrate at all. I am filled with thoughts like what would happen to us if she died. I have my younger sisters, I would be the one to look after for them. It is better when she is alive, I feel as though she is helping me in a way because she inspires me with hope. I feel very much at peace seeing her alive.

Such close emotional connections within caring relationships help to ensure that care is based on (among others) the ethical value of 'responsiveness' (Tronto, 1993). These connections highlight the complexity of caring relations within families and reveal fluidity between the roles of 'care-givers' and 'care-recipients'.

Despite tensions in some families, many young people felt that their caring role had made them 'stronger' and more emotionally mature (Evans, 2013). The life-limiting nature of their parent's illness and the vulnerability of their younger siblings, however, limited the reciprocity of emotional support. Young people caring for parents with HIV felt that they needed to regulate and manage their emotions to avoid their parent becoming worried or stressed, as they knew this could make their illness worse (Evans and Thomas, 2009). Furthermore, young people heading households in Tanzania and Uganda did not feel that they 7 (C) Ruth Evans and Agnes Atim, 5/3/15. Please cite as: Evans, R. and Atim, A. (in press) 'HIV care and interdependence in Tanzania and Uganda', in Ward, N., Ward, E. and Brannelly, P. (Eds), Renewing Care: Critical International Perspectives on the Ethics of Care, The Policy Press. 
could turn to their younger siblings for emotional support and several lacked opportunities to share their feelings with others. In workshops in Tanzania, siblings identified loneliness and the need to suppress their feelings as some of the worst aspects of heading the household: ' $I$ feel lonely when I see my friends being brought up by their parents', and 'I'm forced to be happy all the time, even though I'm sad'. While several siblings were proud of their role heading the household, they expressed ambivalence about having to take on a parenting role for their siblings, while they still considered themselves to be a young person (Evans, 2013).

In Tanzania, many mothers with HIV were concerned about how caring affected their children's emotional wellbeing. Husna said of Juliette's caring responsibilities:

She has a big burden on her young shoulders. I sometimes feel she is overwhelmed by worry. She thinks a lot about me and I think she dreads the day I will die because she will have to provide for her younger sisters. [...] I am sad but I have no choice. Ifeel sorry for her because I feel she is carrying the burden of someone else's responsibility, but that someone else isn't there.

Juliette perceived her caring responsibilities as 'daunting' at times, but felt a moral obligation to support her mother since their relatives stigmatised the family and they lacked alternative sources of support: "The responsibilities are many and I am still young. At times it is daunting. But there is no one else to help so I have to do it”.

Similarly, some of the young people heading households commented on the loneliness and emotionally demanding nature of the care they provided for younger siblings:

(C) Ruth Evans and Agnes Atim, 5/3/15. Please cite as: Evans, R. and Atim, A. (in press) 'HIV care and interdependence in Tanzania and Uganda', in Ward, N., Ward, E. and Brannelly, P. (Eds), Renewing Care: Critical International Perspectives on the Ethics of Care, The Policy Press. 
"When I have all these responsibilities at home, firstly, I think of my parents. When I think about my parents, I get pain in my heart. Therefore when I have these negative thought, I reach a point of losing hope. I say to myself 'why am I here just alone?'. However, since [NGO] are teaching us about perseverance, how can we get out of this situation, I persevere because I am not alone." (Hamisa, young woman, aged 19 caring for her young cousin in Tanzania).

Thus, despite the development of interdependent, reciprocal caring relations, mutual trust and responsibility within families affected by HIV, some mothers and young people simultaneously perceived care as a 'burden' which could have negative physical, emotional and educational impacts on young people. The 'diminished autonomy' of care-givers here can be regarded as a consequence of a lack of alternative co-resident 'care-givers', the limited formal safety nets available to families affected by HIV in East Africa, and global power inequalities that limit the capacity of the 'provider', creating a secondary level of dependency (Kittay, 2002).

\section{Peer support, caregiving and the participation of PLHA 'service users' in healthcare}

Opportunities for marginalized groups to meet, share experiences and develop peer support in safe spaces may be empowering for individuals. Peer support among those who identify with a particular health identity is often focused on coming to terms with the diagnosis, sharing embodied experiences and learning about biomedical health and treatment issues associated with their condition (Beckmann and Bujra, 2010). Many women in Tanzania regularly attended peer support groups, which they felt provided opportunities for women to share

(C) Ruth Evans and Agnes Atim, 5/3/15. Please cite as: Evans, R. and Atim, A. (in press) 'HIV care and interdependence in Tanzania and Uganda', in Ward, N., Ward, E. and Brannelly, P. (Eds), Renewing Care: Critical International Perspectives on the Ethics of Care, The Policy Press. 
experiences and give informal advice about HIV-related issues, including adherence to treatment, nutrition and gaining access to informal material support. Similarly, orphaned young people caring for their siblings in Tanzania, who received support from an NGO, commented on the importance of peer support in helping them to cope with the loss of their parents and in continuing in their caring roles:

"I felt very bad because losing both parents, I was sad for about four months. I was thinking of my parents. But I had to get used and leave it, and be like others, because others lose their parents as well. So we were exchanging ideas with other youths like me who have lost their parents, on how to live, we exchanged ideas and [...] we got used to it”. (Rickson, aged 19, caring for two younger siblings in Tanzania).

Peer support can also foster collective mobilisation and action to challenge discrimination and barriers to participation. Indeed, the research from Tanzania suggests that sustained youth-led community action helped to reduce the stigma and harassment that orphaned youth experienced in Kagera region, north-western Tanzania (Clacherty and Donald, 2006; Madoerin, 2008).

PLHA in Uganda engaged in home-based care from the peak of the epidemic in the early 1990s, in order to reduce barriers to care, provide peer support and bring healthcare to those who were unable to travel to a clinic. PLHA played a crucial role in providing comprehensive non-clinical nursing, palliative, psychosocial and spiritual care to their peers. With the scaleup of anti-retroviral therapy (ART, often referred to as ARVs) from the mid-2000s onwards, many PLHA became home-based caregivers and community support agents based in health

(C) Ruth Evans and Agnes Atim, 5/3/15. Please cite as: Evans, R. and Atim, A. (in press) 'HIV care and interdependence in Tanzania and Uganda', in Ward, N., Ward, E. and Brannelly, P. (Eds), Renewing Care: Critical International Perspectives on the Ethics of Care, The Policy Press. 
facilities in order to provide support in adherence to treatment (Cataldo et al., 2008). Such community support roles help to reduce the likelihood of PLHA who have tested positive subsequently failing to return to health facilities to receive treatment and other services. The greater participation of PLHA in healthcare provision was largely instigated as a means of addressing the limited access to HIV information, services and care available to PLHA in Uganda at the time.

The research suggests that peer-led care and support activities became a key way for PLHA to participate in healthcare service provision, in recognition of each other's common vulnerabilities and interdependence. Participants involved in healthcare delivery reported that they were motivated by their own experiences of living with HIV and their wish to increase access to healthcare services. For example, Eunice's experiences of gaining access to treatment when she most needed it inspired her to 'save other lives' by enabling other PLHA to access to treatment:

"When I tested positive in 1993, I knew that was the end of my life. By then drugs were very expensive that I couldn't afford, my husband had just died and I was pregnant. There were no PMTCT programs yet at that time, my daughter got infected and later died when she was four. My CD4 ${ }^{1}$ went down to 21 at the time government started providing free $A R V$ in 2002 and I was the first client to register to get $A R V$ from Lira hospital my number is 001. Since then I decided to do all I can to save lives and stop other children and adults from dying as my husband and child did." 
Healthcare providers and policymakers in Uganda, as well as care-recipients and caregivers, saw PLHA's involvement in healthcare as necessary to increase access to care for all those who needed it. Indeed, involvement by service users in the delivery of healthcare and support services may help to reduce the burden of care on dysfunctional healthcare systems in postconflict, resource-constrained settings, such as in Northern Uganda. The research suggests that PLHA have played an important role in shifting the health system paradigm from service delivery 'for the community' to 'by the community' (Sarkar, 2010:3). The roles PLHA undertook included: acting as service delivery agents and point of contacts at the community level; providing care and support services; working alongside health workers in health facilities; and client referral, tracking and follow up to increase access to health services. PLHA also coordinated and facilitated linkages between households, the community, health facilities, NGOs, policymakers and development partners.

The research suggests that PLHA's involvement in delivering HIV prevention, treatment, care and support services led to increased uptake of HIV services and a reduction in stigma in the study locations. Increased participation of PLHA in providing care and support can also directly benefit PLHA and caregivers, as well as healthcare providers. As we found in the research on young people's caring roles in families affected by HIV, the caring relations that developed between PLHA in Uganda enhanced emotional ties and were based on mutual trust and the ethical values of 'empathic understanding' and 'responsiveness'. John, for example, commented on the strong sense of empathy and understanding of the needs of PLHA that he experienced by his peers providing home-based care, in the context of high levels of stigma and discrimination: 
"I am here today because of this man [a fellow participant in the focus group]. He broke into the house, where my family had locked me up for days, so that nobody could see me because it would bring shame to the family. He counselled me, carried me on his bicycle to hospital and even attended to me in the hospital, until I could stand up and walk again. I will do anything to help a fellow PLHA because of what he did to $m e ”$.

Service users' 'empathic understanding' of the needs of their peers helped to ensure that PLHA care and support was 'people-centred' and responsive to their needs, which is especially important in post-conflict settings, where people feel they have lost everything. As Bella pointed out:

"I visit clients in their homes, bath, wash their clothes, collect water, cook, put food on the table and talk to them especially for bedridden clients. This is the service one needs most when bedridden. I was cared for and supported a lot by peers when I was bedridden. I know how valuable it was in my life, that is why I feel I should provide care to someone who needs it”.

Despite these benefits of participation, the increased involvement of service users in delivering healthcare and support services, however, can also be seen as fulfilling neoliberal donor-driven agendas of promoting participation, providing alternative service delivery and shifting responsibility for care from the state onto unpaid caregivers, who are mostly women and girls (McIlwaine, 2007; Ogden et al., 2006). This raises the question of the role of the state and global institutions and donors, and whether PLHA, the majority of whom are unpaid interdependence in Tanzania and Uganda', in Ward, N., Ward, E. and Brannelly, P. (Eds), Renewing Care: Critical International Perspectives on the Ethics of Care, The Policy Press. 
volunteers, should be expected to take on such healthcare delivery and care and support roles, when they are already struggling to provide for their own households. Indeed, the detrimental impact of PLHA's caregiving roles on their own livelihoods was highlighted as a key issue by women in Uganda. As a result of feedback discussions with participants, Agnes (second author) helped the women to establish a 'Care for the Carers' organisation that secured donor funding to support the agricultural livelihoods of 220 caregivers living with HIV in Northern Uganda.

The wider question remains, however, of whether, by PLHA adopting these roles in HIV care and support and healthcare delivery, the state, global institutions and donors are absolved from having to train and pay healthcare professionals to provide these services. An ethic of care perspective offers a political argument for the values of care to represent the starting point for the development of social policies and interventions in all sectors and social institutions, including healthcare, social care, community development and family practices (Sevenhuisjen, 2000; Barnes, 2006). Such a political argument for care would re-imagine democratic life and envision a rather different 'caring democracy' (Tronto, 2013) than the existing market-driven reliance on PLHA volunteers to provide unpaid healthcare services and make up for gaps in funding, human resources and service provision in the global South. Furthermore, the research found that PLHA's participation in healthcare service delivery in Uganda was highly gendered and often reinforced conventional gender roles and norms. Home-based care tasks that involved physical and emotional labour, such as bathing, personal care, domestic chores and providing counselling and psychosocial dimensions of support, were often constructed as 'women's work'. Men's involvement in healthcare was usually limited to conventional male-dominated roles, such as building a house for a weak PLHA in

(c) Ruth Evans and Agnes Atim, 5/3/15. Please cite as: Evans, R. and Atim, A. (in press) 'HIV care and interdependence in Tanzania and Uganda', in Ward, N., Ward, E. and Brannelly, P. (Eds), Renewing Care: Critical International Perspectives on the Ethics of Care, The Policy Press. 
the community or giving health talks with fellow men in places where men usually socialise. As a man living with HIV explained, “In my home I don't cook, I don't collect water or sweep the house, how do you expect me to take care of a bedridden patient? What will people think about me doing a woman's work?" Men were also more likely than women to be involved in paid healthcare roles, such as working as expert clients, health facility-based health educators, in village health teams and so on, which were associated with a higher status than home-based care and were rewarded through an income or a bicycle. Dominant gender norms could thus be reinforced through PLHA's increased participation in healthcare and peer support activities.

While our research suggests that developing peer support and living more positively with HIV was important in reducing isolation and may enhance PLHA's 'relational autonomy', it is unclear how this may translate into wider collective action and politicization in campaigning and advocacy beyond the local level. Although peer support groups and peerled home-based and clinic-based care and support activities were highly valued, they were not usually linked to national networks of PLHA or to transnational activism. Beckmann and Bujra (2010) found that access to anti-retroviral therapy enabled PLHA in Tanzania to 'pass' as 'normal' and conceal their illness from others. This may mean, however, that people no longer identify as PLHA and disengage from peer support and activist activities. Our research suggests that despite the high level of involvement of PLHA in care and support activities at local level, their participation in HIV care and support decision-making processes, policy and advocacy at national and global scales has been limited to date. 
Several advocacy initiatives are ongoing to raise awareness of caregivers' issues and the 'burden of care' on women in the context of HIV. Agnes (the second author), has participated in several global forums on HIV care and support including at the United Nations General Assembly Special Session meetings on HIV and AIDS in New York in recent years. A global Caregivers Action Network was established by key stakeholders in 2009 and Agnes established the Caregivers Action Network Africa at the 2012 International AIDS Conference in Washington DC in order to further develop policy, research and caregivers' mobilization in Africa.

A number of challenges to PLHA's participation in global and national policies and decisionmaking processes on HIV care and support however remain (Evans and Atim, 2011). The inclusion of the care and support of PLHA in the 2005 Universal Access to anti-retroviral therapy targets and in the global care agenda of the 2009 United Nations Commission on the Status of Women were major steps forward in recognising the holistic needs of PLHA. In practice, however, medical treatment activities are much more visible and quantifiable and the achievement of measurable targets, such as universal anti-retroviral therapy access targets and Millennium Development Goal 6, are considered a priority for governments, international donors and United Nations agencies. This has resulted in recent years in an overwhelming emphasis on the scale-up of anti-retroviral therapy in funding and programme responses, to the detriment of the care and support agenda. This has been accompanied by limited civil society advocacy on care and support issues compared with treatment activism. Weak global governance of HIV care and support activities, such as the lack of a powerful guiding institution at global level with clear responsibilities for care and support, has hindered implementation. Within the United Nations care and support is seen as a crossinginterdependence in Tanzania and Uganda', in Ward, N., Ward, E. and Brannelly, P. (Eds), Renewing Care: Critical International Perspectives on the Ethics of Care, The Policy Press. 
cutting issue with no single lead agency and no inter-agency task team responsible for care and support aspects of the HIV response.

Further challenges relate to perceptions and attitudes towards HIV and care. While increased access to anti-retroviral therapy has led to a welcome reduction in AIDS-related mortality and PLHA accessing treatment who have an adequate, nutritional diet are now able to lead relatively 'normal' lives, this has resulted in a strong perception that care and support services are no longer required. HIV is increasingly viewed as a chronic illness that can be effectively managed through bio-medical intervention, rather than as a terminal illness. Narrow understandings of care among policymakers and practitioners and the fact that most care-givers are women and girls hinder the development of care services and support for PLHA. The lack of priority accorded to HIV care and support by healthcare institutions, policymakers and government reflects gendered assumptions about women's 'natural' (and hence unpaid) roles in caring for ill and disabled family members and the widespread devaluing of care due to its association with privacy, emotion and the 'othering' of those in need (Sevenhuisjen, 2000). Such perspectives conflict with a feminist ethic of care that recognises the importance of care for all human beings and value it as everyone's responsibility (Tronto, 1993; 2013). Finally, unequal gender and generational relations in many cultural contexts mean that the voices of women, girls and boys who are caregivers and/or living with HIV are often marginalised in decision-making processes from the macroto the micro-levels.

\section{Conclusion}

(C) Ruth Evans and Agnes Atim, 5/3/15. Please cite as: Evans, R. and Atim, A. (in press) 'HIV care and interdependence in Tanzania and Uganda', in Ward, N., Ward, E. and Brannelly, P. (Eds), Renewing Care: Critical International Perspectives on the Ethics of Care, The Policy Press. 
Our research in Tanzania and Uganda suggests that children and young people and women living with HIV, who are usually constructed as 'dependents', 'care-recipients' or 'service users', play crucial roles in providing reciprocal emotional support, guidance, health and practical care for family members and peers living with HIV. Indeed, the two-way process of care-giving and care-receiving often led to close emotional ties, reciprocity, interdependence and a high level of responsiveness, challenging binary assumptions about the identities and practices of 'care-givers' and 'care-receivers'. The research also reveals, however, the intensity of intimate caring relations and problems of social isolation and inadequate resources facing families affected by HIV. This may cause tensions and contradictory feelings about a perceived 'burden of care' that may be difficult to manage (Evans and Thomas, 2009). These conflicts can severely constrain care-givers' ability to provide 'good care' (Tronto's, 1993), resulting in 'diminished autonomy' for caregivers and care-recipients. This sense of 'diminished autonomy' (Fine and Glendinning, 2005) and the disempowerment of those involved in caring relationships is further compounded by the second level of dependency (Kittay, 2002) related to inequalities in access to healthcare and welfare support at local, national and global scales.

Our research suggests, however, that peer support among families affected by HIV and the participation of PLHA in healthcare delivery and care-giving in East Africa may have several benefits, including helping to promote empowerment and reduce feelings of dependency on family members, thereby alleviating potential tensions and emotional pressures within caring relations and the risk of 'domination' and abandonment (Kittay, 2002). PLHA care-givers in Uganda were motivated to provide the best care they could because they knew that they may develop such care needs themselves in future, thereby fostering an environment of 'reciprocal interdependence in Tanzania and Uganda', in Ward, N., Ward, E. and Brannelly, P. (Eds), Renewing Care: Critical International Perspectives on the Ethics of Care, The Policy Press. 
social co-operation' (ibid, p.271). Indeed, the research suggests that the participation of people living with HIV in healthcare provision, home-based care and peer support groups can enhance 'relational autonomy' for both care-givers and care-recipients, although such initiatives often play out in highly gendered ways. Gendered and generational power imbalances could be reinforced, as well as contested, through the care and peer support that children and PLHA provide.

The increased involvement of 'service users' in delivering healthcare and support services raises important questions about the role of the state, global institutions and donors, and whether the participation of people living with HIV in healthcare is merely fulfilling the neoliberal donor-driven agenda of providing alternative service delivery (McIlwaine, 2007) and shifting responsibility for care from the state onto unpaid caregivers, who are mostly women and girls. While PLHA are increasingly taking on crucial roles in HIV prevention, care and support within local communities in resource-constrained, post-conflict settings, such as in Northern Uganda, their participation in strategic decision-making processes at the national and global levels is limited. The research therefore highlights the need for an ethic of care that recognises and values women's, girls' and boys' care work, places the values of care at the centre of the development of health and social care policies and practices and addresses the structural inequalities and gendered power imbalances that restrict the participation of people living with HIV, especially caregiving women and girls, at local, national and global scales. As Tronto (2013, p.169) argues, this involves re-imagining democratic life as ongoing practices and institutions in which all citizens are engaged and "presumes that relational selves, who need ongoing participation as both receivers and givers of care, will be central in making judgments about responsibility".

(c) Ruth Evans and Agnes Atim, 5/3/15. Please cite as: Evans, R. and Atim, A. (in press) 'HIV care and interdependence in Tanzania and Uganda', in Ward, N., Ward, E. and Brannelly, P. (Eds), Renewing Care: Critical International Perspectives on the Ethics of Care, The Policy Press. 


\section{Endnotes}

1. CD4, also known as helper T-cells, act as a co-ordinator of the immune response in the body. HIV destroys infected CD4+ T-cells leading to an overall weakening of the immune system and can also be indicative of the success or failure of anti-retroviral therapy (WHO, 2014). In 2006, the World Health Organization recommended that the criteria for the initiation of anti-retroviral therapy (ART) in adults in resource-limited settings is for ART to be considered when the CV4 cell count was between 200 and 350 and for those with less than 200 to be treated irrespective of the clinical stage of HIV-associate disease, since this is associated with a significant increase in opportunistic infections and death (WHO, 2006). These guidelines were revised upwards in 2010 to recommend that all adolescents and adults including pregnant women with HIV infection and CD4 counts of equal to or under 350 cells/mm3, should start ART, regardless of the presence or absence of clinical symptoms. Those with severe or advanced clinical disease (WHO clinical stage 3 or 4) should start ART irrespective of their CD4 cell count (WHO, 2010).

\section{Acknowledgements}

We are grateful to all the participants in Tanzania and Uganda for sharing their experiences with us. We thank Sophie Bowlby and Sally Lloyd-Evans for their support during Agnes' doctoral research and gratefully acknowledge the ESRC, Royal Geographical Society (with the Institute of British Geographers) and University of Reading for funding the research reported here. Agnes wishes to thank all the PLHA fraternity in Northern Uganda particularly NACWOLA Lira; Agago and Lira Network of People Living with HIV; the Healthcare 
professionals, political leaders and NGO workers in Lira and Agago districts for their valuable information that made her research possible.

\section{References}

Barnes, M. (2006) Caring and Social Justice, Basingstoke: Palgrave MacMillan.

Beckmann, N. and Bujra, J. (2010) "The politics of the queue": The politicization of People living with HIV/AIDS in Tanzania, 41(6), 1041-1064.

Bondi, L. (2008) On the relational dynamics of caring: a psychotherapeutic approach to emotional and power dimensions of women's care work. Gender, Place and Culture 15(3): 249-265.

Cataldo, F., Museheke, M. And Kielmann, K (2008). New challenges for home-basedcare providers in the context of ARTroll-out in Zambia. XVII International AIDS Conference, Mexico City, 2 -8 August, Abstract number: MOPE0167.

Chimwaza, A. and Watkins, S. (2004) Giving care to people with symptoms of AIDS in rural sub-Saharan Africa, AIDS Care, 16(7), 795-807.

Clacherty, G. and Donald, D. (2006) Impact Evaluation of the VSI (Vijana Simama Imara) Organisation and the Rafiki Mdogo Group of the HUMULIZA Orphan Project, Nshamba, Tanzania. Johannesburg, South Africa, Novartis Foundation for Sustainable Development and Regional Psychosocial Support Initiative.

Davidson, J. and Milligan, C. (2004) Embodying emotion sensing space: introducing emotional geographies. Social and Cultural Geography, 5 (4), 523-532.

Evans, R. (2013) 'Young people's caring relations and transitions within families affected by HIV', in J. Ribbens McCarthy, C. Hooper and V. Gillies (eds), Family Troubles? Exploring changes and challenges in the family lives of children and young people, Bristol: The Policy Press, pp.233-243.

Evans, R. (2012) 'Safeguarding inherited assets and enhancing the resilience of young people living in child- and youth-headed households in Tanzania and Uganda', African Journal of AIDS Research, 11(3): 177-189.

Evans, R. (2011) "We are managing our own lives...": Life transitions and care in siblingheaded households affected by AIDS in Tanzania and Uganda', Area, 43 (4): 384-396.

Evans, R. and Atim, A. (2011) Care, Disability and HIV in Africa: diverging or interconnected concepts and practices?, Third World Quarterly, 32(8), 1437-1454.

Evans, R. and Becker, S. (2009) Children Caring for Parents with HIV and AIDS: Global Issues and Policy Responses, Bristol: The Policy Press.

21

(C) Ruth Evans and Agnes Atim, 5/3/15. Please cite as: Evans, R. and Atim, A. (in press) 'HIV care and interdependence in Tanzania and Uganda', in Ward, N., Ward, E. and Brannelly, P. (Eds), Renewing Care: Critical International Perspectives on the Ethics of Care, The Policy Press. 
Evans, R. and Thomas, F. (2009) 'Emotional interactions and an ethic of care: caring relations in families affected by HIV and AIDS', Emotions, Space and Society, 2, pp.111119.

Fine, M. and Glendinning, C. (2005) 'Dependence, independence or inter-dependence? Revising the concepts of 'care' and 'dependency', Ageing and Society, 25, 601-621.

Kittay, E.F (2002) 'When caring is just and justice is caring: justice and mental retardation', in E.F. Kittay and E. Feder (eds), The Subject of Care: Feminist Perspectives on Dependency, Lanham, MD: Rowman and Littlefield, pp 257-276.

Madoerin, K. (2008) Mobilising Children and Youth into Their Own Child-and Youth-led Organisations. Johannesburg, South Africa, Regional Psychosocial Support Initiative.

Mackenzie, C. and Stoljar, N. (eds) (2000) Relational Autonomy: Feminist Perspectives on Autonomy, Agency and the Social Self. Oxford: Oxford University Press.

McIlwaine, C. (2007) From local to global to transnational civil society: reframing development perspectives on the non-state sector, Geography Compass, 1(6), 1252-1281

Morris, J. (1991) Pride Against Prejudice: Transforming Attitudes to Disability, Philadelphia: New Society Publishers.

Ogden, J., Esim, S. and Grown, C. (2006) Expanding the care continuum for HIV/AIDS: bringing carers into focus, Health Policy and Planning, 21(5) 333-342.

Sarkar, S. (2010) Community engagement in HIV prevention in Asia: going from 'for the community' to 'by the community' - must we wait for more evidence? Sexually Transmitted Infections, 86(1), 2-3.

Sevenhuisjsen, S. (2000) Caring in the third way: the relation between obligation, responsibility and care in Third Way discourse, Critical Social Policy, 20(1), 5-37.

Sevenhuijsen, S. (1998) Citizenship and the Ethics of Care. Feminist Considerations on Justice, Morality and Politics. London and New York: Routledge.

Shakespeare, T. (1993) Disabled people's self-organisation: a new social movement? Disability, Handicap and Society 8(3), 249-264.

Tronto, J. (1993) Moral Boundaries. A Political Argument for an Ethic of Care, New York and London: Routledge

Tronto, J. (2013) Caring Democracy. Markets, Equality and Justice. New York and London: New York University Press.

World Health Organization (WHO) (2006) Antiretroviral Therapy for HIV Infection in Adults and Adolescents: Recommendations for a Public Health Approach 2006 Revision, Geneva: World Health Organization.

(c) Ruth Evans and Agnes Atim, 5/3/15. Please cite as: Evans, R. and Atim, A. (in press) 'HIV care and interdependence in Tanzania and Uganda', in Ward, N., Ward, E. and Brannelly, P. (Eds), Renewing Care: Critical International Perspectives on the Ethics of Care, The Policy Press. 
WHO (2010) Antiretroviral Therapy for HIV Infection in Adults and Adolescents: Recommendations for a Public Health Approach 2010 Revision, Geneva: World Health Organization.

WHO (2014) CD4+ T-Cell counting Technology,

http://www.who.int/diagnostics_laboratory/faq/cd4/en/ [accessed 24/09/14].

(c) Ruth Evans and Agnes Atim, 5/3/15. Please cite as: Evans, R. and Atim, A. (in press) 'HIV care and interdependence in Tanzania and Uganda', in Ward, N., Ward, E. and Brannelly, P. (Eds), Renewing Care: Critical International Perspectives on the Ethics of Care, The Policy Press. 